\title{
Observações aos comentários sobre o artigo intitulado "Políticas públicas, distribuição de renda e pobreza no meio rural brasileiro no período de 1995 a 2005".
}

\author{
Renata C. Moreira \\ Marcelo J. Braga \\ João Ricardo F. de Lima
}

O presente documento tem objetivo de apresentar observações aos comentários realizados pelo professor Rodolfo Hoffmann ao artigo de Moreira et al., publicado na Revista de Economia e Sociologia Rural de out.-dez. de 2009 (vol. 47, $\mathrm{n}^{\circ} 4$ ). Inicialmente, os autores agradecem o interesse do professor Hoffmann pelo trabalho e apresentação dos questionamentos e esperam que o debate a cerca dos aspectos metodológicos possam trazer contribuições significativas para a consolidação dos grupos de pesquisa na área. A seguir são pontuadas cada uma das questões levantadas pelo professor Rodolfo Hoffmann.

1. Com relação aos valores negativos na tabela 1 , na p. 935 da medida de desigualdade $L$ de Theil, é importante ressaltar que uma vantagem no uso dos índices $L$ e $T$ de Theil está na possibilidade de sua decomposição em componentes que dizem respeito às desigualdades entre e intra-grupos, quando uma população é dividida em G grupos sócio-econômicos de interesse. Assim, o índice $L$ pode ser genericamente indicado pela soma de $L_{\mathrm{e}}$, que corresponde à desigualdade obtida caso não existisse desigualdade entre os indivíduos de um mesmo grupo sócio-econômico, com $L_{\mathrm{i}}$, que representa a desigualdade dentro dos grupos. A desigualdade total $(L)$ pôde ser calculada de acordo com a Equação (4) da página 928, que se encontra repetida a seguir:

$L=-\sum_{g} \beta_{g} \cdot \ln \alpha_{g}+\sum_{g} \beta_{g} \cdot L_{g}$

onde $L_{g}$ é o índice L do grupo g 
772 - Observações aos comentários sobre o artigo intitulado "Políticas públicas, distribuição de renda e pobreza no meio rural brasileiro no período de 1995 a 2005".

$\alpha_{g}$ é a razaõ entre a renda média do grupo g e a renda média global $\alpha_{g}=\bar{X}_{g} / \mu$

$\beta_{g}$ é a proporção da população ocupada no grupo $g$ $\beta_{\mathrm{g}}=n_{g} / N$

Deve-se enfatizar o fato do primeiro termo da soma poder assumir valores positivos ou negativos, de acordo com a razão entre a renda média do grupo e a renda média global. Neste sentido, à medida que grupos com rendas médias bem superiores à global aumentassem seu peso na média ponderada, e que o efeito das desigualdades entre os membros do grupo passasse a ser também significativo, reduzindo a renda média global, passa o índice $L$ auferir valores negativos. Esta opção de variáveis se justificou pela ênfase dada às assimetrias na distribuição entre estratos de renda, e os valores negativos podem ser interpretados como de um cenário típico de extrema concentração de renda e estratificação social, o que se aproxima bem da realidade brasileira, principalmente em se tratando das áreas rurais.

Vale ainda salientar que estes valores foram obtidos pela forma em que foram definidas as variáveis, da sua agregação em grupos de renda padronizados pelo Instituto Brasileiro de Geografia e Estatística (IBGE), e do pressuposto de distribuição de probabilidades aproximadamente uniforme dentro dos grupos, desprezando o segundo termo na soma para isolar o efeito das desigualdades entre grupos de renda. Ao se adotar este procedimento, tornou-se possível que as parcelas negativas dominassem as positivas. Existem outros estudos em que valores negativos podem ocorrer com relação à definição das variáveis. Um exemplo é o trabalho de Lima e Resende (2008) recentemente publicado, no qual o professor fez comentários muito semelhantes, e os autores devidamente explicaram a possibilidade existente do índice $L$ assumir valores negativos, conforme Lima e Resende (2009).

2. As Figuras 2, 3 e 4 do artigo apresentam a evolução das curvas de Lorenz para todo o período, de 1995 a 1998 , e de 2001 a 2005, conjugando dois movimentos em sentidos distintos. O primeiro, no período de 1995 a 1998, representando um aumento na concentração da distribuição de renda. O segundo, entre 2001 e 2005, representando uma clara redução na concentração da renda, não 
significativa o suficiente para alterar a estrutura das distribuições acumuladas que permanecem desfavoráveis para a população de menor renda. Percebe-se claramente uma quebra estrutural, com uma perda de renda da população mais pobre situada no lado da cauda esquerda, para a população mais rica, do lado da cauda direita, entre os anos de 1998 e 2001, representando uma mudança na estrutura da concentração de renda no meio rural. Pelas Figuras, os autores destacam esta mudança estrutural desfavorável aos $60 \%$ mais pobres, situados na cauda inferior da distribuição, cuja soma total de renda representa menos que $15 \%$ da renda total, agravando as desigualdades rurais. Isto se deu em um período marcado por fortes impactos da adoção das políticas neoliberais em concordância com instituições internacionais entre as quais um dos maiores representantes é o Fundo Monetário Internacional (FMI), como descrito na página 933. A relação entre estas e a mudança estrutural reforçando a persistente desigualdade e estratificação da sociedade rural brasileira sim foram foco da análise econômica pretendida, e não a reta pontilhada que aparece e que de fato é o bissetor do primeiro quadrante, observe que o eixo das abscissas começa em 0,1 e não em 0 (zero)! A mudança foi apenas na origem de $(0 ; 0)$ para $(0,1 ; 0)$ para desenhar o gráfico, que o Gretl fez automaticamente. Mas os valores de rendas nulas foram devidamente inseridos nos cálculos da forma apresentada no artigo.

3. As estimativas do coeficiente de gini foram de fato realizadas, como citado no artigo em questão, "incluindo pessoas sem rendimentose sem declaração", em que foram atribuídos valores nulos a ambas as rendas. A justificativa por esta escolha se deu, primeiro pela baixa representatividade do número de pessoas sem declaração com relação ao tamanho da amostra, não sendo superior a $1 \%$ em média. $\mathrm{O}$ procedimento está pontuado na página 932 :

"A sub-declaração dos rendimentos mais elevados leva a uma sub-estimativa do grau de desigualdade da distribuição de renda e da pobreza. Aspectos ligados à metodologia de coleta de dados também podem levar a uma sub-estimativa da renda total declarada pelos indivíduos entrevistados. Para o caso da população rural, exclui a área rural da região norte, importante área onde se estende a 
774 - Observações aos comentários sobre o artigo intitulado "Políticas públicas, distribuição de renda e pobreza no meio rural brasileiro no período de 1995 a 2005".

fronteira agrícola do país. Por ter como base uma semana específica de referência não permite que se capte a variabilidade das atividades agrícolas no país ao longo do ano"(MOREIRA; et al, 2009. p. 932).

E, por fim, apreciando por outro lado, a grande representatividade da população rural sem renda, em média de $45 \%$ para todos os anos, chegando ao máximo de 50\%, em 1996, leva a impactos nas estimativas que não devem ser desprezados na análise da questão agrária proposta, como é difundido nas estimativas que fazem usos de logaritmos como os índices de Theil e a aproximação lognormal para a distribuição de renda. A significância estatística destes impactos tanto em populações urbanas, como rurais, já foi foco de outros estudos como o de Kassouf (1994) que usa o procedimento de Heckman para avaliar a necessidade de incluir os residentes rurais que não auferem renda nas estimativas das taxas salariais. Apesar de que, felizmente para os pesquisadores, os avanços no emprego dos instrumentais econométricos não descaracterizam as análises anteriores com base em métodos menos complexos.

4. A frase foi escrita no sentido de corresponder à área abaixo da reta de equidistribuição, "abaixo" da reta de uma distribuição de perfeita igualdade. Isso corresponde à área de igualdade, abaixo da curva de Lorenz, que nesse caso corresponde ao triângulo inferior do primeiro quadrante. É essa que deve estar no denominador nos cálculos do índice de Gini, como esclarecido depois no próprio texto "(área do triângulo ABC que é 0,5)"(MOREIRA et al, 2009, p. 926). Vista pelo ângulo da área que distancia a curva de Lorenz da reta de equiidistribuição, área de desigualdade, seria equivalente à curva de perfeita desigualdade, caso em que o coeficiente de Gini assume o valor unitário. São duas formas de dizer a mesma coisa, "uma vendo o copo meio cheio e a outra, meio vazio" como se diz em forma de ditado popular.

5. Na p. 927 do artigo, houve um equívoco na construção da frase que levou a uma interpretação errônea a respeito do índice de Gini atender "ao critério da sensibilidade decrescente a transferências, sendo mais sensíveis a transferências de renda na cauda inferior da distribuição que na superior". A sensibilidade do índice de Gini, como sabido, e descrito de forma mais detalhada em artigo do próprio Hoffmann (1992) é proporcional à densidade de freqüência relativa dos logaritmos das 
rendas, ou no caso de uma distribuição contínua, à densidade de probabilidade do logaritmo da renda. Para uma distribuição lognormal, por exemplo, esta densidade se maximiza na renda mediana. Desta forma, como o próprio artigo descreve "o índice de Gini é mais sensivel a esse tipo de transferência regressiva quando esta envolve pessoas cujas rendas estão na parte da distribuição onde é máxima a freqüência de relativa dos logaritmos da rendas."(HOFFMANN, 1992. p. 297). Haverá, portanto, um intervalo de rendas relativamente baixas em que a sensibilidade do índice de Gini crecerá com a renda como destacado também em Hoffmann (1994).

No entanto, como o autor mesmo adverte que, excluindo as rendas muito próximas de zero, esta sensibilidade será substancialmente maior para rendas relativamente baixas, em torno da mediana, do que para rendas elevadas, o que pode ser razoável para a análise pretendida. Neste mesmo artigo são expostas duas razões pelas quais reafirmaram a escolha por não descartar o índice de Gini como medida de desigualdade. A primeira diz respeito à vantagem da pouca sensibilidade às rendas muito próximas de zero considerando que não correspondem à renda real das pessoas. Por exemplo, as pessoas ocupadas e que respondem por não remuneradas das famílias de pequenos agricultores, entre outros empreendimentos familiares. O que leva à segunda razão, de ser possível incluir estas rendas declaradas nulas em seus cálculos, permitindo comparações entre distribuições contendo esta parte, tão representativa no caso do Brasil. O que não pode ser dito para os índices de Theil, especialmente ao $L$-Theil, cuja maior sensibilidade é inútil, pois calculado com os logaritmos da razão entre rendas médias, não permite uma comparação desta.

6. De fato, no segundo parágrafo da p. 934 do artigo de Moreira et al. (2009), o conceito de dominância entre curvas de Lorenz está invertido nos anos, onde se lê 1995 (2001), troca-se por 1998 (2005), e viceversa. No entanto, a análise de concentração e desconcentração permanece correta, existe um movimento de concentração de renda de 1995 a 1998, e a partir de 2001 até 2005 , o movimento que se observa é o de desconcentração. No entanto, como alertado na página 933, como as curvas se interceptam, a análise de dominância fica prejudicada em todo o período. 
776 - Observações aos comentários sobre o artigo intitulado "Políticas públicas, distribuição de renda e pobreza no meio rural brasileiro no período de 1995 a 2005".

7. Além das fontes de subestimativas já discutidas nos trabalhos econométricos, a escolha pelo agrupamento também se apoiou em critérios operacionais. Para trabalhar com os microdados desagregados em períodos longos, como o do estudo (10 anos) com amostra em torno da média de 21.195.185 observações por ano (considerando a população estimada com a expansão das amostras), somaria um banco de dados com 709.044.033 observações! Realizar os cálculos neste nível de desagregação requereria software especializado, recursos de máquina e bases de dados que não estavam disponíveis à época.

Optou-se por este agrupamento por ser compatível com os recursos disponíveis, com o uso do software livre Gretl (2007). Contou-se igualmente com os grupos padrões de renda publicados nas tabelas disponibilizadas gratuitamente pelo IBGE. O uso da forma padronizada pelo IBGE de publicação dos resultados das pesquisas ainda traz a vantagem de propiciar comparações, é possível comparações com as tabelas de 2009, por exemplo, veja no endereço eletrônico http://www.ibge.gov.br/home/estatistica/populacao/ trabalhoerendimento/pnad2009/pnad brasil 2009.pdf. Estas publicações estão disponíveis para todos os anos do período, assim como para os anos mais recentes (2006 a 2009), passíveis de serem incorporados à análise.

8. Os autores não consideraram relevante repetir dentro do limitado espaço para a exposição da análise pretendida esta informação por considerar que encontra-se bem difundida entre os trabalhos. Mas de fato, já era de conhecimento dos mesmos que do ano de $2001 \mathrm{em}$ diante, a PNAD redefiniu as áreas rurais de acordo com os resultados do censo demográfico de 2000. Esta distorção a partir de 2001 acarreta certo grau de perda de comparabilidade com os anos anteriores, que ocorre proporcionalmente à distância que o ano se encontra do ano censitário anterior. Assim como há reponderações após todos os anos de censos funcionando como um ajuste nos parâmetros estatísticos que delineiam as amostras. Adotou-se, portanto, a postura bastante difundida entre os pesquisadores que trabalham com esta base de dados, como explicitam Neder e Mariano da Silva (2004), transcrita na seguinte citação.

"É provável que em quatro anos o perímetro urbano de muitos municípios tenha se ampliado, mas 
Renata C. Moreira, Marcelo J. Braga e $\cdot 777$ João Ricardo F. de Lima, outubro de 2010

desprezaremos aqui este efeito levando-se em conta que muitas vezes esta ampliação não reflete necessariamente o processo de urbanização no inicio da década de 1990, sendo decorrência muitas vezes dos interesses das municipalidades em ampliar a arrecadação de impostos via cobrança de IPTU."(NEDER; MARIANO DA SILVA; 2004; p.473474).

As limitações com relação aos dados disponíveis para as análises econométricas consistem ainda uma das grandes limitações deste campo de estudos. Este fato reforça a necessidade fundamental de que análises deste tipo se construam com bases sólidas sobre uma concepção teórica e dentro de um contexto histórico-social bem definido. Apenas desta forma haverá meios de verificação da coerência dos resultados da análise estatística, justificando seu uso na economia.

9. O estudo levou em conta a renda total da população acima de 10 anos residente nas áreas rurais como descrito na página 932 . A afirmação que segue citada na íntegra, para não ser descontextualizada, se deu para justificar esta escolha.

“...por considerar que, devido às características específicas da agricultura tradicional e familiar, que ocupa a maioria da população rural, a população não economicamente ativa também é representativa na geração da renda, assim como dos gastos, como o caso das aposentadorias rurais." (MOREIRA, et AL, 2009; p.932).

Este trecho tem base nos trabalhos de Delgado (2001) e Neder (2001) que estudaram, dentre outros aspectos, o impacto das aposentadorias rurais após a constituição de 1988 sobre a distribuição da renda no espaço rural, como foi explicado no terceiro parágrafo da página 924 mais detalhadamente. Delgado (2001) expande a análise incluindo o papel dos assentamentos rurais e dos agricultores familiares nestas transformações no "setor rural". E é no sentido de Delgado que se usa este termo, refletindo sobre suas relações sócio- 
778 - Observações aos comentários sobre o artigo intitulado "Políticas públicas, distribuição de renda e pobreza no meio rural brasileiro no período de 1995 a 2005".

econômicas que se dão no espaço rural inerentes à questão agrária, objeto do artigo.

Estas relações, apesar das mudanças que vêm de fato sendo observadas, no período em análise ainda eram predominantemente marcadas pelas atividades agrícolas. Os autores concordam que "área rural" e "setor agrícola" não são idênticos, no entanto, avaliam que exibem forte correlação visto que as atividades agrícolas se dão em sua maioria no espaço rural, com fortes impactos sobre a distribuição de renda e as condições de pobreza da população que lá reside, trabalhando ou não neste setor, como bem caracterizado por Neder (2001). Desta forma, o modelo produtivo agrícola estimulado via políticas públicas, tem efeitos significativos sobre as condições de vida da população rural, e este foi aspecto central do debate pretendido. Para tal, é preciso aprofundar a reflexão teórica, em busca de maior compreensão a respeito das forças econômicas que estão em jogo, e como elas relacionam-se entre si.

Já adentrando à crítica relacionada ao termo "agricultura tradicional", usou-se a descrição dada por Lamounier (1994) na página 923, que inclui parte dos agricultores familiares, quilombolas, indígenas, entre outros grupos populacionais que historicamente estiveram à margem do processo de formação e implementação das políticas agrícolas. Como mencionado, pelo censo agropecuário de 2006 (IBGE, 2009), os autores ainda consideram esta população somada com os demais agricultores familiares como a maioria, visto que somam $74,4 \%$ da população ocupada, ou seja, de cada 10 ocupados na agropecuária, sete estão na agricultura familiar, que emprega 15,3 pessoas por 100 hectares. E mesmo que isto some um montante que gira em torno de $52 \%$ da população residente em áreas rurais em 2006, o que deve ser maior para os anos em análise, isto ainda é a maioria. Além disso, representa $84,4 \%$ dos estabelecimentos totais, respondendo por $38 \%$ do valor total da produção, sem entrar no mérito de sua contribuição na geração dos alimentos que compõem a cesta básica, consumidos pelos brasileiros.

Este movimento das atividades econômicas, de agrícolas para não-agricolas, no espaço rural não é desprezado, no entanto, pelos autores, que julgam importante este objeto de estudo e análises. Assim como o dos trabalhadores urbanos que se empregam em atividades agrícolas que vêm ampliando seus impactos sobre a população rural ao longo dos anos. Não foi foco da análise pretendida neste artigo, que se limitou à análise da distribuição da renda e da 
Renata C. Moreira, Marcelo J. Braga e 779 João Ricardo F. de Lima, outubro de 2010

questão da pobreza rural no contexto das políticas do período de 1995 a 2005, se restringindo ao espaço limite da revista em uma reflexão do processo histórico em curso, não tendo a pretensão de adentrar nestes méritos.

10. Os cálculos podem ser reproduzidos organizando as Tabelas publicadas no Volume Brasil para Pessoas de 10 anos ou mais de idade e valor do rendimento mensal das pessoas de 10 anos ou mais de idade, por sexo, segundo a situação do domicílio e as classes de rendimento mensal - Brasil, em séries históricas com os anos do período em análise. Estas tabelas encontram-se disponibilizadas publicamente no endereço de internet citado no item(7), para todos os anos do período. Alguns valores estão resumidos na Tabela 1.

Tabela 1 -Dados usados nas estimativas para os anos de 1995 e 2001, Brasil: pessoas de 10 anos ou mais de idade, valor rendimento médio mensal das pessoas de 10 anos ou mais de idade segundo situação de domicilio rural.

\begin{tabular}{l|r|r|r|l|r|r|r}
\hline & $\begin{array}{r}\text { Pessoas de 10 } \\
\text { anos ou mais } \\
\text { de idade } \\
\text { (PIA) }\end{array}$ & $\begin{array}{r}\text { Valor do } \\
\text { rendimento } \\
\text { médio } \\
\text { mensal das } \\
\text { PIA (R\$) }\end{array}$ & Ano & $\begin{array}{l}\text { Classes de rendimento } \\
\text { mensal }\end{array}$ & $\begin{array}{r}\text { Pessoas de } \\
10 \text { anos ou } \\
\text { mais de } \\
\text { idade }\end{array}$ & $\begin{array}{r}\text { Valor do } \\
\text { rendimento } \\
\text { médio } \\
\text { mensal das } \\
\text { PIA (R\$) }\end{array}$ & Ano \\
\hline Rural Total & 24191302 & 104 & 1995 & Total & 25250035 & 247 & 2001 \\
\hline Sem rendimento & 11665627 & 0 & 1995 & Sem rendimento & 9559564 & 0 & 2001 \\
\hline Sem declaração & 224162 & 0 & 1995 & Sem declaração & 187967 & 0 & 2001 \\
\hline Até 1/2 salário mínimo & 1606853 & 33 & 1995 & Até 1/2 salário mínimo & 2257102 & 51 & 2001 \\
\hline $\begin{array}{l}\text { Mais de 1/2 a 1 salário } \\
\text { mínimo }\end{array}$ & 4080347 & 89 & 1995 & $\begin{array}{l}\text { Mais de 1/2 a 1 salário } \\
\text { mínimo }\end{array}$ & 4347470 & 158 & 2001 \\
\hline $\begin{array}{l}\text { Mais de 1 a 2 salários } \\
\text { mínimos }\end{array}$ & 3723186 & 153 & 1995 & $\begin{array}{l}\text { Mais de 1 a 2 salários } \\
\text { mínimos }\end{array}$ & 2239541 & 261 & 2001 \\
\hline $\begin{array}{l}\text { Mais de 2 a 3 salários } \\
\text { mínimos }\end{array}$ & 1311565 & 258 & 1995 & $\begin{array}{l}\text { Mais de 2 a 3 salários } \\
\text { mínimos }\end{array}$ & 930298 & 439 & 2001 \\
\hline $\begin{array}{l}\text { Mais de 3 a 5 salários } \\
\text { mínimos }\end{array}$ & 856713 & 398 & 1995 & $\begin{array}{l}\text { Mais de 3 a 5 salários } \\
\text { mínimos }\end{array}$ & 573665 & 688 & 2001 \\
\hline $\begin{array}{l}\text { Mais de 5 a 10 salários } \\
\text { mínimos }\end{array}$ & 492445 & 719 & 1995 & $\begin{array}{l}\text { Mais de 5 a 10 salár ínimos } \\
\text { mín }\end{array}$ & 296921 & 1211 & 2001 \\
\hline $\begin{array}{l}\text { Mais de 10 a 20 salários } \\
\text { mínimos }\end{array}$ & 155436 & 1414 & 1995 & $\begin{array}{l}\text { Mais de 10 a 20 salários } \\
\text { mínimos }\end{array}$ & 90463 & 2463 & 2001 \\
\hline $\begin{array}{l}\text { Mais de 20 salários } \\
\text { mínimos }\end{array}$ & 74968 & 3582 & 1995 & $\begin{array}{l}\text { Mais de 20 salários } \\
\text { mínimos }\end{array}$ & 40263 & 6753 & 2001 \\
\hline
\end{tabular}

Fonte: IBGE, Diretoria de Pesquisas, Coordenação de Trabalho e Rendimento, Pesquisa Nacional por Amostra de Domicílios 1995 e 2001

Dentro da proposta do estudo publicado, de análise da realidade da desigualdade e pobreza rurais, foi possível captar as relações entre estas variáveis, 
780 - Observações aos comentários sobre o artigo intitulado "Políticas públicas, distribuição de renda e pobreza no meio rural brasileiro no período de 1995 a 2005".

assim como a evolução do comportamento relativo de ambas no tempo, em coerência com outros estudos semelhantes, como os de Neder e Mariano da Silva (2004), Marinho e Soares (2003) e Hoffmann(2005). Esta discussão e comparação passível de se realizar dentro dos limites impostos pelos estudos exibirem diferenças com relação às definições das variáveis, base de dados e metodologias, encontram-se dispostos nas páginas 936 e 940. Reproduzindo alguns dos resultados para uma breve analise de adequação, a Tabela 2 a seguir apresenta os resultados do estudo para o ano de 2001, juntamente com os resultados de outros estudos semelhantes realizados com os dados das PNADs para o mesmo ano. Destaca-se o comportamento relativo semelhante aos indicadores calculados para os residentes em áreas rurais dos estados da região Nordeste por Neder e Mariano da Silva (2004),aproximando-se da analise destes.

Tabela 2. Coeficientes de Gini e de Proporção de Pobres $(H)$, Hiato da Pobreza $(H P)$ e Severidade da Pobreza (P2) calculados para a população residente em áreas rurais para o ano de 2001

\begin{tabular}{l|ccc}
\hline Índice & 2001(Eq.6) & $\mathbf{2 0 0 1}^{*}$ & $\mathbf{2 0 0 1}^{* *}$ \\
\hline $\boldsymbol{G I N I}$ & 0,6364 & 0,5038 & 0,5938 \\
\hline $\boldsymbol{H}$ & 0,6132 & 0,5182 & 0,385 \\
$\boldsymbol{H P}$ & 0,2879 & 0,2501 & - \\
$\boldsymbol{P 2}$ & 0,2205 & 0,1560 & - \\
\hline $\boldsymbol{e}(\boldsymbol{H} / \boldsymbol{r m})$ & $-0,7348$ & $-0,8569$ & $? 0,84$ \\
$\boldsymbol{E}(\boldsymbol{h p} / \boldsymbol{r m})$ & $-1,1298$ & $-1,0724$ & - \\
$\boldsymbol{E}(\boldsymbol{p} 2 / \boldsymbol{r m})$ & $-0,6108$ & $-1,2064$ & - \\
\hline $\boldsymbol{e}(\boldsymbol{H} / \boldsymbol{g})$ & 0,3398 & 0,3958 & 1,84 \\
$\boldsymbol{e}(\boldsymbol{h p} / \boldsymbol{g})$ & 1,9850 & 1,9573 & - \\
$\boldsymbol{e}(\boldsymbol{p} 2 / \boldsymbol{g})$ & 3,2075 & 3,4811 & - \\
\hline
\end{tabular}

Fonte: adaptado de Moreira et al (2009)

*Pessoas residentes em áreas rurais na região NE calculado pela aproximação quadrática sem agregação em grupos de renda (NEDER; MARIANO DA SILVA, 2004, p. 482). 
** rendimento domiciliar per capita no Brasil (urbano e rural) usando aproximação lognormal e com rendas positivas (HOFFMANN, 2005, p. 280).

Apesar das discrepâncias quando se inclui a população urbana e exclui as rendas nulas como nos valores calculados por Hoffmann (2005), os resultados concordam em aspectos fundamentais. A saber, que a população residente nestas áreas continua enfrentando duras condições de sobrevivência, com expressivo montante de pessoas acima de 10 anos que não auferem renda (em média de $45 \%$ para todos os anos para a população rural), e da proporção de pobres $(H)$ dada a linha de pobreza, que variou entre $58 \%$ e $62 \%$ para os anos calculados; que o hiato da pobreza da renda rural e a severidade da mesma é mais sensível à distribuição da renda que ao crescimento dela, característica de um cenário com baixos níveis médios de renda e de extrema concentração da mesma que ainda persiste, entre outras conclusões sintetizadas nas páginas 941 e 942.

É neste aspecto que se encontra a principal contribuição pretendida, que em momento nenhum se propôs a esgotar o assunto, mas como é possível dentro dos limites de um artigo, construir mais elementos com base na teoria associada à aplicação de métodos estatísticos ampliando as evidências empíricas para o Brasil e refinando a reflexão teórica e o debate sobre os paradigmas em questão. Apesar de concordarem no diagnóstico da condição da pobreza rural, cada abordagem teórica evidencia certos determinantes em detrimento a outros, o que em conseqüência, aponta para diferentes prioridades nas escolhas entre políticas alternativas de combate à pobreza. A escola neoclássica, por exemplo, de forma resumida aposta na universalização da educação e nas livres forças de mercado para a resolução de tal problema. Por outro lado, outras escolas de pensamento econômico mais realistas defendem a necessária intervenção do Estado na economia, no intuito de atenuar os problemas distributivos associados ao desenvolvimento das forças produtivas. Entender qual delas é mais adequada para analisar e intervir sobre a realidade brasileira é fundamental não apenas ao debate da questão, mas também ao próprio desenvolvimento da ciência econômica.

Dando continuidade a este estudo, outras publicações já foram realizadas, onde foram testadas outros ferramentais teóricos e empíricos para a análise da questão, sendo que nenhuma rejeitou os resultados publicados. Destaque pode ser dado às Teses de doutorado em Economia Aplicada defendidas por Lima (2008) e Moreira (2009). Nesta ultima, as elasticidades-pobreza da renda média 
782 - Observações aos comentários sobre o artigo intitulado "Políticas públicas, distribuição de renda e pobreza no meio rural brasileiro no período de 1995 a 2005".

e do Gini foram calculadas para toda população por Unidades da Federação no período de 1996 a 2007, como foi reproduzido na Figura 1. A Tabela 3 contém a legenda com os códigos associados às Unidades Federativas pelo IBGE.

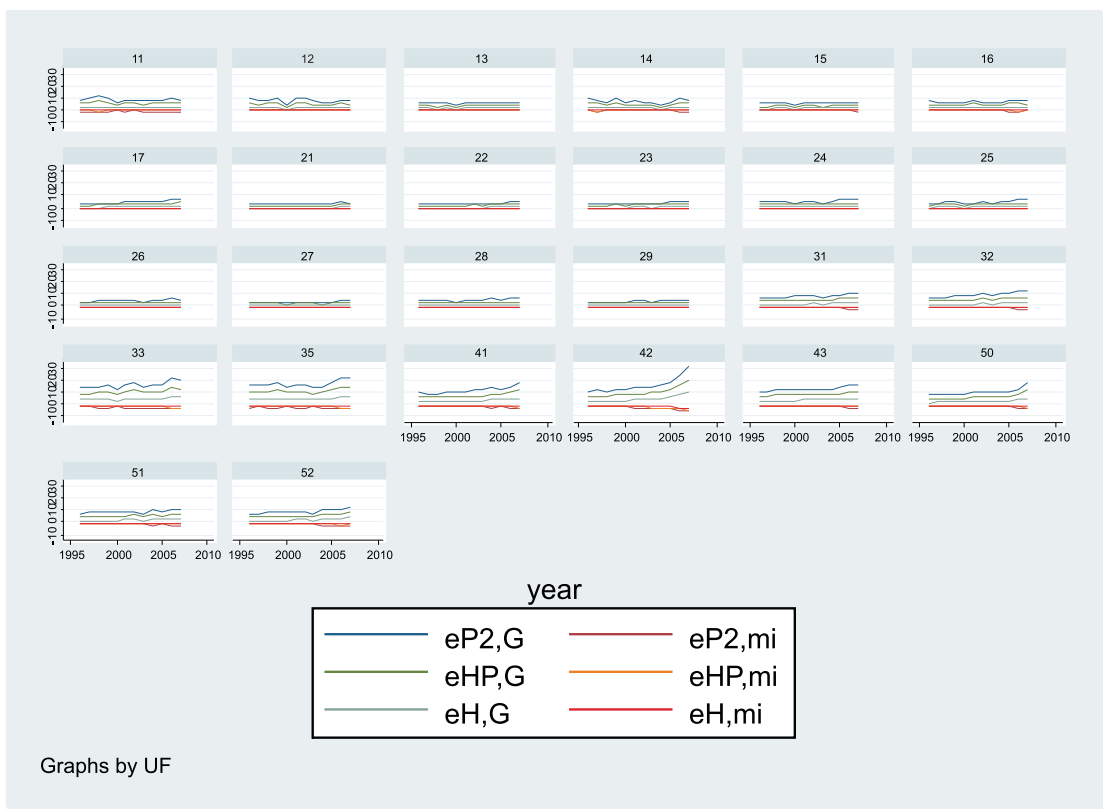

Fonte: Resultados da pesquisa de doutorado (MOREIRA, 2009)

Figura 1 - Comportamento das elasticidades renda ( $\left.e_{-}, \mathrm{mi}\right)$ e Gini $\left(e_{-}, \mathrm{G}\right)$ de $H, H P$ e P2 para estados brasileiros entre os anos de 1996 e 2007

Tabela 3. Legenda com os Códigos Associados às Unidades Federativas (UF) 
Renata C. Moreira, Marcelo J. Braga e $\cdot \mathbf{7 8 3}$ João Ricardo F. de Lima, outubro de 2010

\begin{tabular}{l|l|l|l|l|l}
\hline UF & código & UF & código & UF & código \\
\hline Rondônia & 11 & Ceará & 23 & Rio de Janeiro & 33 \\
\hline Acre & 12 & Rio Grande do Norte & 24 & São Paulo & 35 \\
\hline Amazonas & 13 & Paraíba & 25 & Paraná & 41 \\
\hline Roraima & 14 & Pernambuco & 26 & Santa Catarina & 42 \\
\hline Pará & 15 & Alagoas & 27 & Rio Grande do Sul & 43 \\
\hline Amapá & 16 & Sergipe & 28 & Mato Grosso do Sul & 50 \\
\hline Tocantins & 17 & Bahia & 29 & Mato Grosso & 51 \\
\hline Maranhão & 21 & Minas Gerais & 31 & Goiás & 52 \\
\hline Piauí & 22 & Espírito Santo & 32 & & \\
\hline
\end{tabular}

Fonte: Elaboração da autora a partir dos dados das PNAD de 1996 a 2007 e do Censo demográfico 2000, IBGE, excluído o Distrito Federal.

Os resultados destacam característica marcante da pobreza no Brasil como um todo, que se repetiram quando desagregado em nível de estados, como observado também por Hoffman (2005) incluindo as áreas urbanas. Ou seja, a pobreza no Brasil, assim como nas suas unidades federativas é mais sensível a reduções na desigualdade da distribuição da renda, que ao crescimento médio desta. Este efeito traz importante reflexão aos formuladores de políticas públicas, assim como corrobora com aspectos teóricos das escolas de pensamento mais realistas, discussão que se encontra mais aprofundada em Moreira (2009).

Outro resultado que deve ser ressaltado, relaciona-se às baixas elasticidades relativas aos estados com maiores desigualdades na distribuição da renda e menor renda media, como os das regiões Nordeste e Norte, em relação aos do Sudeste e Sul. Isso significa que é mais difícil reduzir a pobreza justamente nos estados onde esta condição é mais acentuada e, portanto, os 
784 - Observações aos comentários sobre o artigo intitulado "Políticas públicas, distribuição de renda e pobreza no meio rural brasileiro no período de 1995 a 2005".

que mais precisam. O comportamento reproduz-se nos outros dois índices, do hiato e da severidade da pobreza, assim como para as áreas rurais, sendo a diferença apenas nos valores.

Portanto, a análise histórico-estruturalista proposta continua consistente, por mais que outros métodos mais complexos surjam a todo o momento. Deve-se ainda levar em conta que os erros de amostragem das amostras complexas das PNADs tendem a ser maiores que os mesmos erros em amostragens aleatórias simples, e que aquelas são publicadas freqüentemente com novos fatores de ponderação, o que significa para os cientistas que os cálculos dos anos referentes à tais mudanças deve ser todo refeito! Felizmente, estas fontes de erro não são suficientes para descartar as análises anteriores, o que seria insustentável do ponto de vista científico.

\section{Referencias Bibliograficas}

DELGADO, G. C. Expansão e modernização do setor agropecuário no pósguerra: um estudo da reflexão agrária. Estudos Avançados. 15(43): 157-172, 2001.

GRETL. Disponível em: <http://gretl.sourceforge.net/> em março de 2007.

HOFFMANN, R. (1992) "Sensibilidade das medidas de desigualdade a transferências regressivas.” Pesquisa e Planejamento Econômico 22: 289-304.

. (1994) O índice de atkinson e a sensibilidade das medidas de desigualdade a transferências regressivas. R. Econometria Rio de .Janeiro v. 14., n 2, p.159-176 novembro 1994/março 1995

. (2005) Elasticidade da Pobreza em Relação à Renda Média e à Desigualdade no Brasil e nas Unidades da Federação. Economia, v6, no2, jul/ dez, 255-286, 2005.

IBGE (2009) Censo Agropecuário 2006: Agricultura Familiar (primeiros resultados - Brasil, grandes regiões e unidades da Federação). Rio de Janeiro, IBGE.

KASSOUF, A. L.(1994) The wage rate estimation using Heckman procedure. Revista de Econometria. Rio de Janeiro, v.14, n.1, abr./out., 1994. p. 89-107. 
Renata C. Moreira, Marcelo J. Braga e $\cdot \mathbf{7 8 5}$ João Ricardo F. de Lima, outubro de 2010

LAMOUNIER, B.(Coord.) (1994) Determinantes politicos da política agrícola: um estudo de atores, demandas e mecanismos de decisão. IPEA: estudos de política agrícola no 9, $1994.58 \mathrm{p}$.

LIMA, J. R. F. (2008) Efeitos da pluriatividade e rendas não-agrícolas sobre a pobreza e desigualdade rural na região Nordeste. Tese de doutorado em Economia Aplicada, Departamento de Economia Rural, Universidade Federal de Viçosa. Ano de obtenção 2008.

LIMA, M. e RESENDE, M. (2008) Banking and regional inequality in Brazil: na empirical note. Revista de Economia Política 28 (4): 669-677. . (2009) Réplica ao comentário de Rodolfo Hoffmann. Revista de Economia Política, v. 29, n. 3 (115) jul-set/2009. p.254-255.

ARINHO, E. \& SOARES, F. Impacto do crescimento econômico e da concentração de renda sobre a edução da pobreza nos estados brasileiros. In XXXI Encontro Nacional de Economia, Porto Seguro, BA, ANPEC, 2003.

MOREIRA, R. C. (2009) Desigualdade, crescimento econômico e armadilhas da pobreza no Brasil: 1996 a 2007. Tese de doutorado em Economia Aplicada, Departamento de Economia Rural, Universidade Federal de Viçosa. Ano de obtenção 2009.

MOREIRA, R. C. et al. (2009) Políticas públicas, distribuição de renda e pobreza no meio rural brasileiro no período de 1995 a 2005. Revista de Economia e Sociologia rural, vol. 47, no 4, p. 919-944, out.-dez. de 2009.

NEDER, H. D. (2001) Os efeitos das atividades não agrícolas na distribuição de renda do meio rural do Brasil. XXXIX Congresso Brasileiro de Economia e Sociologia Rural,SOBER, Anais em CD-ROM, Recife, agosto de 2001.

NEDER, H. D. \& MARIANO DA SILVA, J. L. (2004) Pobreza e distribuição de renda em áreas rurais: uma abordagem de inferência. RER Rio de Janeiro, vol. $42, \mathrm{n}^{\circ} 03$, p. 469-486, jul/set 2004. 